\title{
Effect of age and environmental conditions on the movement characteristics of Pacific oyster (Crassostrea gigas) trochophores
}

\author{
M. Suquet ${ }^{1,{ }^{*}}$, F. Rimond ${ }^{1}$, J. Cosson ${ }^{2}$, J. Wilson-Leedy ${ }^{3}$, L. Lebrun ${ }^{1}$, I. Queau ${ }^{1}$, C. Mingant ${ }^{1}$, C. Fauvel ${ }^{4}$ \\ ${ }^{1}$ Ifremer, PFOM/LPI, UMR 100, Argenton, France \\ ${ }^{2}$ Faculty of Fisheries and Protection of Waters, South Bohemian Research Center of Aquaculture and \\ Biodiversity of Hydrocenoses, University of South Bohemia in Ceske Budejovice, Vodnany, Czech Republic \\ ${ }^{3}$ Department of Biological Sciences and Center for Reproductive Biology, University of Idaho, Moscow, ID, USA \\ ${ }^{4}$ Ifremer, BOME Department, Palavas, France \\ *: Corresponding author : Marc Suquet, email address : $\underline{\text { marc.suquet@ifremer.fr }}$
}

\begin{abstract}
:
The movement characteristics of Pacific oyster trochophores have received very little coverage in the scientific literature. Described here are not only changes in the swimming characteristics of Crassostrea gigas trochophores (size: $53-77 \mu \mathrm{m}$ ) in relation to time after fertilization and to interfemale variation but also the effects of salinity and $\mathrm{pH}$ on movement characteristics. The percentage of motile trochophores was measured on images obtained through a dissecting microscope and the Velocity Average Path (VAP) was assessed using a Computer Assisted Sperm Analysis (CASA) system. At $20^{\circ} \mathrm{C}$, the first movements of the trochophores were observed at $6.5 \mathrm{~h}$ post-fertilization. The mean $( \pm \mathrm{SD})$ percentage of swimming trochophores and the VAP observed in seawater at $11.5 \mathrm{~h}$ post-fertilization were $85 \pm 10 \%$ and $146 \pm 75 \mu \mathrm{m} \mathrm{s}^{-1}$, respectively $(\mathrm{n}=8$ females). Significant interfemale variation in the percentage of motile trochophores (range: $66 \pm 16-93 \pm 3 \%$ ) and in the VAP $\left(55 \pm 47-180 \pm 90 \mu \mathrm{m} \mathrm{s}^{-1}\right)$ was detected. Most of the trochophores were motile in a $9 \%$ salinity solution. Adjusting the $\mathrm{pH}$ of the seawater to values from 5.10 to 9.08 had no effect on swimming characteristics. The present study shows that the movement of oyster trochophores exhibits high plasticity in relation to environmental conditions because the highest percentages of swimming trochophores and optimal velocity values were recorded within large ranges of salinity and $\mathrm{pH}$. Further research is required to determine whether the swimming performances of trochophores can be used to assess embryo quality in commercial hatcheries.
\end{abstract}




\section{Introduction}

The first stage of bivalve larvae, called the trochophore stage, is ciliated and swims continuously. Trochophores possess a band of cilia, the prototroch, which girdles the larva and has a double function: propulsion and feeding (Widows, 1991). The movement characteristics of marine bivalve trochophores have been scarcely studied, with only basic movement characteristics of these larvae (Mileikovsky, 1973) and the effect of their exposure to toxicants reported (Horiguchi et al., 1998). Effects of cryopreservation on swimming behaviour of these larvae have also been studied (Paniagua-Chavez and Tiersch, 2001).

Trochophore swimming is generally continuous as observed in the scallop (Pecten maximus; Cragg, 1980). The efficacy of cilia to generate movement is related to larval body size (Cragg, 1980; Chia et al., 1984). The percentage of one-day-old swimming larvae of the marine polychaete (Arenicola cristata) increased when salinity was enhanced (Richmond and Woodin, 1996). The effect of salinity on larval speed was also reported in the mactrid bivalve, Spisula solidissima (Mann et al., 1991). In addition, increasing water temperature was reported to enhance the swimming velocity of blue mussel (Mytilus edulis) larvae (Sprung, 1984).

Regarding oysters, the swimming velocity of American oyster (Crassostrea virginica) larvae was reported to range from 100 to $300 \mu \mathrm{m} \mathrm{s}^{-1}$ (Hidu and Haskin, 1978) and to be enhanced with an increase of its body size (Dekshenieks et al., 1996). The swimming speed of Pacific oyster larvae was also found to increase from 68 to $279 \mu \mathrm{m}$ in larger animal (Troost et al., 2008).

Techniques used so far to estimate cell movement characteristics have evolved from the subjective estimation of cell displacement in a drop under a dissecting microscope (Mann et al., 1991) to image analysis which provides a rapid and objective measurement (Cosson, 2008). Computer Assisted Sperm Analysis (CASA) devices objectively quantify fine parameters of sperm movement such as velocity and trajectory. Such a technique was used to measure the swimming speed of marine snail (Crepidula fornicata) larvae (Hilbish et al., 1999). Recently, a new CASA system has been developed, consisting of freely accessible software primarily designed for the analysis of fish sperm movement (Wilson-Leedy and Ingermann, 2007). Using this software, changes in the movement velocity provided an early and reliable estimation of the survival of thawed Pacific oyster D-larvae (Suquet et al., 2012).

The current study was designed to assess basic characteristics associated with the movement of Pacific oyster trochophore larvae. Changes in swimming characteristics in relation to time after fertilization and to interfemale variations were investigated. In addition, effects of salinity and $\mathrm{pH}$ on motility characteristics of the trochophores were assessed. 


\section{Materials and methods}

\subsection{Trochophore production}

Oyster larvae were obtained according to the method of Song et al. (2009). Briefly, adult oysters were transferred from a growing site in the natural environment at Aber Benoit to the Argenton experimental hatchery (North Brittany, France) where they were conditioned for sexual maturation. After 6 to 8 weeks, gametes were collected by gonad dissection. Oocytes were concentrated using a $20 \mu \mathrm{m}$ mesh filter and counted $(3 \times 50 \mu \mathrm{l}$ in $1 \mathrm{~L}$ suspension) and 100,000 oocytes were fertilized (using a non-limiting ratio of 500 spermatozoa for one oocyte) in $2 \mathrm{~L}$ seawater beakers by the addition of pooled sperm collected by gonad dissection of two males. For each experiment, trochophores were produced using oocytes collected individually from three females. The trochophores (53 to $77 \mu \mathrm{m}$ diameter, $\mathrm{n}$ $=200$ ) were used for experiments 5 to $23 \mathrm{~h}$ after fertilization at $20 \pm 1^{\circ} \mathrm{C}$. They were concentrated using a $20 \mu \mathrm{m}$ mesh size. Drops of $10 \mu \mathrm{l}$ were placed on a glass slide without a cover slip and the movement of the trochophores was observed.

\subsection{Experimental design}

Trochophore movement was observed at room temperature $\left(20 \pm 1^{\circ} \mathrm{C}\right)$ under a dissecting microscope (Leica MZ 125, 4 x objective, $13800 \pm 1$ 700 lux). The percentage of motile trochophore larvae was visually estimated in triplicate by counting (30 trochophores for each replicate). Velocity was assessed using a microscope connected to a camera (Sony Exwave HAD, with more than 30 trochophores observed for each film). Swimming speed was assessed using a CASA plug-in tool developed for Image J software (Wilson-Leedy and Ingerman, 2007). Larval Velocity Average Path (VAP) was measured on the moving larval population because this parameter was considered to be the most relevant among the different swimming speed parameters generated by the CASA image analysis (Fauvel et al., 2010). The software was first calibrated to oyster trochophores according to Suquet et al. (2012). The VAP values observed for the trochophores of a single female were not significantly different between three successive samplings $(P=0.941)$. The number of consecutive frames used for the analysis (from 10 to 75 ) did not significantly alter the recorded VAP values $(P=0.966)$. Taking into account both of these results, one film was recorded for each condition, and 25 consecutive frames were analysed for each film.

The effect of the age (time after fertilization) of the oyster larvae on the percentage of motile trochophores and on the VAP was measured at 5 to $23 \mathrm{~h}$ after fertilization of the oocytes. Individual variations in the movement characteristics of the trochophores were studied using larvae collected from five different females.

The effect of some environmental parameters on the movement characteristics was studied at 18 to $22 \mathrm{~h}$ after oocyte fertilization. The trochophores were collected from the culture vial by filtration $(20 \mu \mathrm{m})$, and seawater was replaced by the experimental solution via three successive washings $(3 \times 5 \mathrm{ml})$ and filtrations. The movement of the trochophores was 
recorded $1 \mathrm{~min}$ after the last washing. The effect of water salinity was observed after the trochophores had been transferred to solutions of salinities from 3.5 to $34.7 \%$, (conductivity meter: WTW Profiline Cond 197i), obtained after dilution of the seawater in distilled water at an appropriate ratio. The effect of $\mathrm{pH}$ was investigated using seawater buffered with Tris $20 \mathrm{mM}$ and adjusted to various $\mathrm{pH}$ values from 5.10 to 10.10 , by addition of $1 \mathrm{M}$ solutions of $\mathrm{HCl}$ or $\mathrm{NaOH}$.

\subsection{Statistical analysis}

Data are presented as mean \pm standard deviation. The percentages of motile trochophores were arcsin square-root transformed. Means were compared using one or two way ANOVA. When differences were significant, a Tukey a posteriori test was used for mean comparison.

\section{Results}

The first movements of the trochophore larvae were observed $6.5 \mathrm{~h}$ post fertilization (Fig. 1a). A progressive significant increase $(P=0.001)$ of the percentage of motile trochophores was recorded between 6.8 and $11.5 \mathrm{~h}$ post fertilization where the highest percentage of motile trochophores was reached. The maximum VAP was reached through successive steps: from 6.8 to $7.5 \mathrm{~h}$, the VAP remained low (from 30 to $50 \mu \mathrm{m} \mathrm{s}^{-1}$ ) and then increased rapidly to reach a maximum velocity of $260 \mu \mathrm{m} \mathrm{s}^{-1}$ at $11.5 \mathrm{~h}(\mathrm{P}=$ 0.001 ; Fig. 1b). Then, a plateau was recorded up to $23 \mathrm{~h}$ post fertilization for both parameters. A significant interaction was observed between individual females and time post fertilization for the percentage of motile larvae $(P=0.001)$ and VAP $(P=0.001)$. Significant inter-individual variations in the percentage of motile trochophores $(P=0.018$, range $66 \pm$ $16 \%-93 \pm 3 \%)$ and in the VAP $(P=0.001$, range $55 \pm 47-180 \pm 90 \mu \mathrm{m} \mathrm{s}$ ${ }^{1}$ ) were detected (Fig. 2a and b).

The percentage of motile trochophores significantly increased $(P=0.001)$ with increasing salinity from 3.5 to $9.0 \%$ (Fig. 3a). Then, a plateau was observed in the 9.0 to $34.7 \%$ range. After significantly increasing ( $P=$ 0.001 ), maximum values of VAP were measured at salinities ranging from 17.7 to $34.7 \%$ o (Fig. 3b). A significant interaction was observed between individual females and both the percentage of motile trochophores $(P=$ $0.020)$ and swimming velocity $(P=0.001)$. For values between 5.10 and 9.08, the pH did not modify the percentage of motile trochophores (Fig. 4a). At $\mathrm{pH} 10.06$, a significant decrease $(P=0.003)$ in the percent motility was observed. A significant interaction effect was observed between individual females and $\mathrm{pH}$, on the percentage of motile trochophores $(P=0.001)$. The VAP was not significantly modified by $\mathrm{pH}$ values ranging from 5.10 to 10.06 (Fig. 4b). 


\section{Discussion}

The CASA plug-in developed for the software Image $\mathrm{J}$ (Wilson-Leedy and Ingermann, 2007) used in the present study, represents an efficient tool for the assessment of swimming characteristics of cell types from different origins, including marine bivalve embryos at the trochophore stage.

Under natural conditions, the movement of trochophores is a complex interaction between horizontal and vertical movements including seawater currents. The combined effects of these two movement components cannot be simultaneously recorded in a controlled environment. Recording a movement in a three dimensional environment would provide new insights into cell movement studies. However, it remains problematic because it is most often the unrealistic movements and artefacts that are observed (Shiomi et al., 2010), thus biasing the movement characteristics. Furthermore, the horizontal movement velocity of Pacific oyster larvae is similar to its vertical movement velocity (Troost et al., 2008).

In the case of the Pacific oyster, the mean percentage of swimming trochophores and the mean swimming velocity observed in seawater at $20^{\circ} \mathrm{C}$, from $11.5 \mathrm{~h}$ post fertilization, were $85 \pm 10 \%$ and $146 \pm 75 \mu \mathrm{m} \mathrm{s}^{-1}$ respectively ( $\mathrm{n}=8$ females). The percentage of motile cells has been frequently measured in work devoted to sperm movement of marine species (Rurangwa et al., 2004; Cosson, 2008). However, this parameter has only been measured in three studies dedicated to larval swimming performances of molluscs: the first one measured the percentage of swimming American oyster larvae in relation to salinity (Dekshenieks et al., 1996), the second and third ones estimated the survival of frozen/thawed larvae of Pacific oysters (Paniagua-Chavez and Tiersch, 2001; Suquet et al., 2012). The mean VAP of Pacific oyster trochophores assessed in the present study is close to that reported in American oysters at $20^{\circ} \mathrm{C}(100$ to $300 \mu \mathrm{m} \mathrm{s}^{-1}$; Hidu and Haskin, 1978). Higher values (600 to 2,200 $\mathrm{\mu m} \mathrm{s}^{-1}$ ) have been reported in the case of the blue mussel (Troost et al., 2008).

At a rearing temperature of $20^{\circ} \mathrm{C}$, no larval movement was observed before $6.5 \mathrm{~h}$ post fertilization. An increase in the swimming parameters of Pacific oyster trochophores (length ranging from 53 to $77 \mu \mathrm{m}$ ) in relation to time post fertilization has not been reported in the literature. However, some studies have been carried out on older stages: the swimming velocity of Pacific oyster larvae was increased from 700 to $6,500 \mu \mathrm{m} \mathrm{s}^{-1}$ when the animal increased in size from 68 to $279 \mu \mathrm{m}$ (Troost et al., 2008). The swimming velocity of American oyster larvae with a size of $300 \mu \mathrm{m}$ was two to eight times higher than values measured for larvae of $75 \mu \mathrm{m}$ (Hidu and Haskin, 1978). Our results showed that the swimming behaviour of Pacific oyster D-larvae (30 h post fertilization) is very different from that of trochophores : intermittent swimming phases were observed, intercalated with resting periods. This behaviour was confirmed by a low and variable percentage of motile D-larvae $(29 \pm 18 \%)$. In addition, the VAP of the Dlarvae was higher $\left(209 \pm 19 \mu \mathrm{m} \mathrm{s}^{-1}\right)$ than the mean velocity of the trochophores. The changes in the swimming characteristics in relation to time post fertilization may be due to changes in the aggregation of cilia and their beating efficiency (Chia et al., 1984). 
The large inter-female variation in the trochophore swimming characteristics recorded in the present work was confirmed by the frequent interactions observed between individual females and the percentage of motile trochophores and swimming velocity. Individual variations of swimming characteristics were only studied in marine snail larvae but for progeny from different crosses (male $x$ female) : mean swimming speeds differed more than three fold among families (Hilbish et al., 1999). Trochophore movement characteristics may depend on various parameters such as embryo integrity and energy content.

Since the work of Clarke (1934), it has been well known that environmental factors such as salinity, light and temperature may modify the movement of planktonic marine animals. Salinity requirements of Pacific oyster pediveligers have been reported to range from 18 to $30 \%$ (Phelps and Warner, 1990). Pacific oyster trochophores are euryhaline in terms of movement capacity but their velocity is more sensitive to low salinity than is the percentage that are motile, since the highest motile percentage was observed in our study at $9 \%$ while the swimming velocity remained low. The duration of motility for American oyster larvae was enhanced when salinity was increased from 14 to $24 \%$ (Dekshenieks et al., 1996). Furthermore, the swimming velocity of mactrid bivalves increased from 190 to $260 \mu \mathrm{m} \mathrm{s}^{-1}$ with a change in salinity from 20 to $30 \%$ (Mann et al., 1991). The effect of $\mathrm{pH}$ on the swimming characteristics of the Pacific oyster trochophores was very limited in our study, because it only affected the percentage of motile trochophores at a non-physiological value (10.06).

In conclusion, the motility analysis demonstrated that Pacific oyster trochophores show high plasticity in response to environmental constraints, exhibiting a high percentage of swimming trochophores and optimized velocities within large ranges of salinity and $\mathrm{pH}$. The inter-individual variation in swimming performances must be further explored to determine whether this parameter can provide a suitable indicator of embryo quality in commercial hatcheries.

\section{Acknowledgement}

We acknowledge the financial support of the national Centre de Ressources Biologiques, project Cryoaqua (2009-2010). Many thanks to $\mathrm{H}$. McCombie-Boudry for corrections to the English.

\section{References}

Chia, F.S.; Buckland-Nicks, J.; Young, C.M., 1984: Locomotion of marine invertebrate larvae: a review. Can. J. Zool. 62,1205-1222.

Clarke, G.L., 1934: Factors affecting the vertical distribution of copepods. Ecol.

Monogr. 4, 530-540.

Cosson, J., 2008: Methods to analyse the movements of fish spermatozoa and their 
flagella. In: Fish spermatology. Eds: S.M.H. Alavi; J. Cosson; K.

Coward; G. Rafiee, Alpha Science International, Oxford, pp. 63-102.

Cragg, S.M., 1980: Swimming behaviour of the larvae of Pecten maximus (L)

(Bivalvia). J. Mar. Biol. Assoc. U.K. 60, 551-564.

Dekshenieks, M.M.; Hofmann, E.E.; Klinck, J.M.; Powell, E., 1996: Modelling the

vertical distribution of oyster larvae in response to environmental conditions. Mar. Ecol. Prog. Ser. 136, 97-110.

Fauvel, C.; Suquet, M.; Cosson, J., 2010: Evaluation of fish sperm quality. J. Appl.

Ichthyol. 26, 636-643.

Hidu, H.; Haskin, H.H., 1978: Swimming speeds of oyster larvae Crassostrea

virginica in different salinities and temperatures. Estuaries 1, 252-

255.

Hilbish, T.J.; Sasada, K.; Eyster, L.S.; Pechenik, J.A., 1999: Relationship between

rates of swimming and growth in veliger larvae: genetic variance and covariance. J. Exp. Mar. Biol. Ecol. 239, 183-193.

Horiguchi, T.; Imai, T.; Cho, H.S.; Shiraishi, Y.; Morita, M.; Shimizu, M., 1998:

Acute toxicity of organotin compounds to the larvae of the rock shell, Thais clavigera, the disk abalone, Haliotis discus discus and the giant abalone, Haliotis madaka. Mar. Environ. Res. 46, 469-473.

Mann, R.; Campos, B.M.; Luckenbach, M.W., 1991: Swimming rate and responses

of larvae of three mactrid bivalves to salinity discontinuities. Mar. Ecol. Prog. Ser. 68, 257-269.

Mileikovsky, S.A., 1973: Speed of active movement of pelagic larvae of marine

bottom invertebrates and their ability to regulate their vertical position. Mar. Biol. 23,11-17.

Paniagua-Chavez, C.G.; Tiersch T.R., 2001: Laboratory studies of cryopreservation

of sperm and trochophore larvae of the eastern oyster. Cryobiol. 43, 211-223.

Phelps, H.L.; Warner, K.A., 1990: Estuarine sediment bio-assay with oyster pediveliger larvae (Crassostrea gigas). Bull. Env. Cont. Toxicol. 44, 197-204.

Richmond, C.E.; Woodin, S.A., 1996: Short-term fluctuations in salinity: effects on

planktonic invertebrate larvae. Mar. Ecol. Prog. Ser. 133, 167-177.

Rurangwa, E.; Kime, D.E.; Ollevier, F.; Nash, J.P., 2004: The measurement of

sperm motility and factors affecting sperm quality in cultured fish. Aquaculture 234, 1-28.

Shiomi, K.; Narazaki, T.; Sato, K.; Shimatani, K.; Arai, N.; Ponganis, P.J.; Miyazaki, N., 2010: Data-processing artefacts in three-dimensional dive path reconstruction from geomagnetic and acceleration data. Aquat. Biolm. 8, 299-304.

Song, Y.P.; Suquet, M.; Quéau, I.; Lebrun, L., 2009: Setting of a procedure for

experimental fertilization of Pacific oyster (Crassostrea gigas) oocytes. Aquaculture 287, 311-314. 
Sprung, M., 1984: Physiological energetics of mussel larvae (Mytilus edulis). III.

Respiration. Mar. Ecol. Progr. Ser. 18, 171-178.

Suquet, M.; Le Mercier, A.; Rimond, F.; Mingant, C.; Haffray, P.; Labbé, C., 2012: Setting tools for the early assessment of the quality of thawed Pacific oyster (Crassostrea gigas) D-larvae. Theriogenol. 78, 462467.

Troost, K.; Veldhuizen, R.; Stamhuis, E.J.; Wolff, W.J., 2008: Can bivalve veligers

escape from feeding currents of adult bivalves? J. Exp. Mar. Biol. Ecol. 358, 185-196.

Widdows, J., 1991: Physiological ecology of mussel larvae. Aquaculture 94, 147163.

Wilson-Leedy, J.G.; Ingermann, R.L., 2007: Development of a novel CASA system based on open source software for characterization of zebrafish sperm motility parameters. Theriogenol. 67, 661-672. 


\section{Figures}

Fig. 1 Effect of time after fertilization on the movement characteristics of Pacific oyster trochophores $(n=3$ females, more than 30 trochophores observed for each film recorded); a: changes in the percentage of motile trochophores in relation to time after fertilization, b: changes in the Velocity Average Path (VAP) in relation to time after fertilization ( $x$ axis not presented as a real time scale).
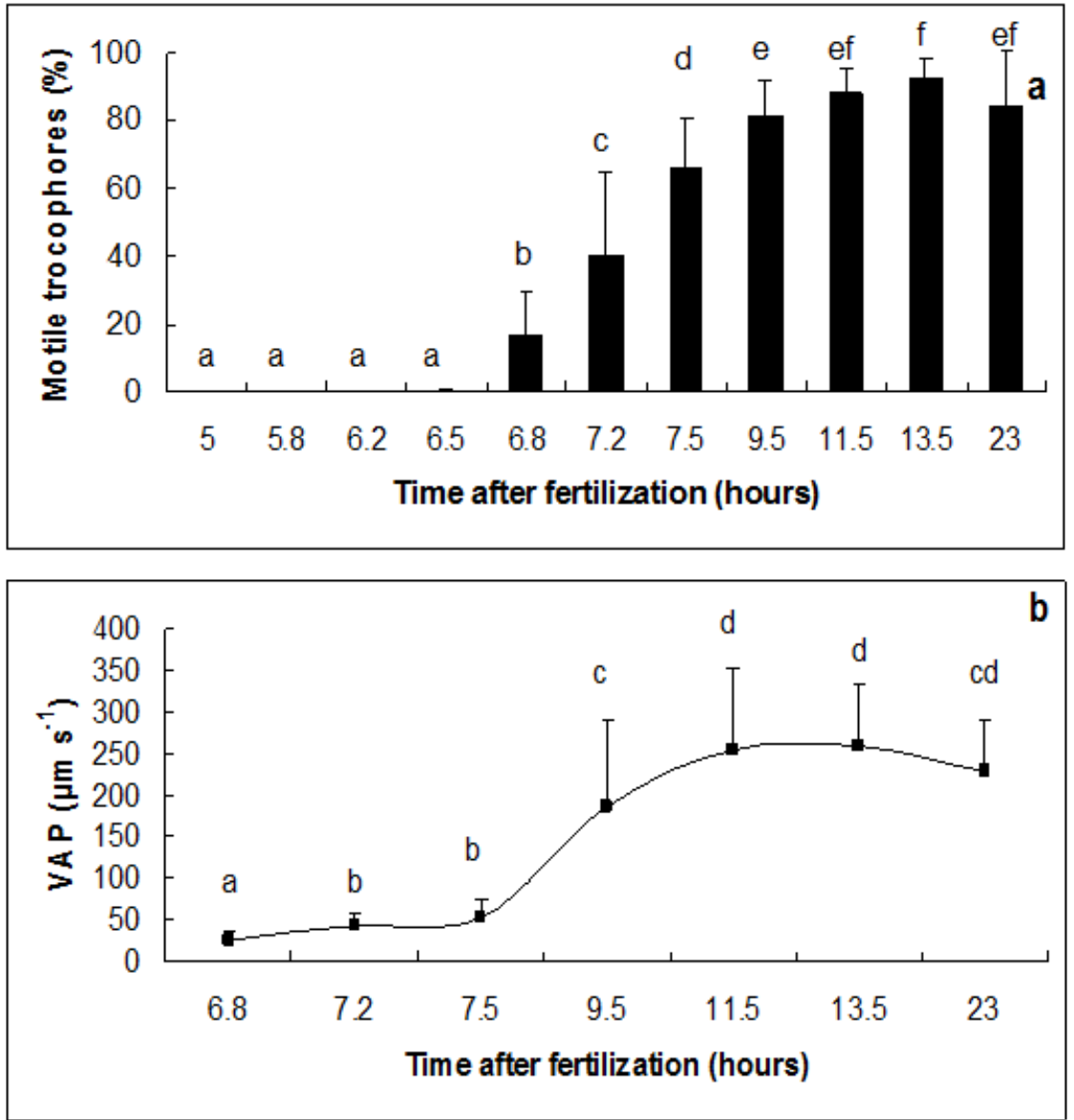
Fig. 2 Inter-female variations in the movement characteristics of Pacific oyster trochophores ( $n=5$ females, more than 30 trochophores observed for each film recorded); a: changes in the percentage of motile trochophores in relation to individual females, $b$ : changes in the Velocity Average Path (VAP) in relation to individual females.
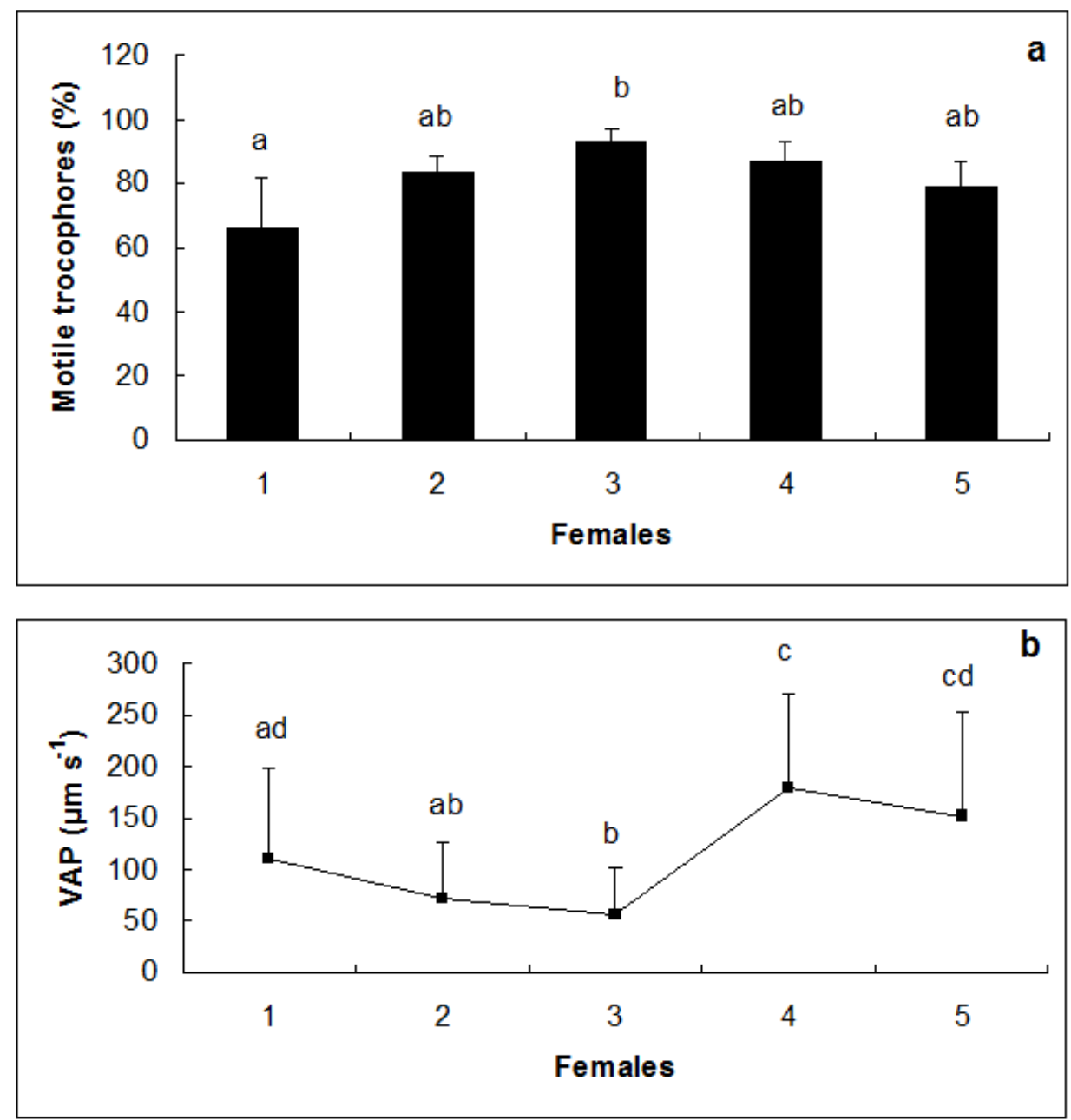
Fig. 3 Effect of water salinity on the movement characteristics of Pacific oyster trochophores ( $n=3$ females, more than 30 trochophores observed for each film recorded); a: changes in the percentage of motile trochophores in relation to salinity, b: changes in the Velocity Average Path (VAP) in relation to salinity.
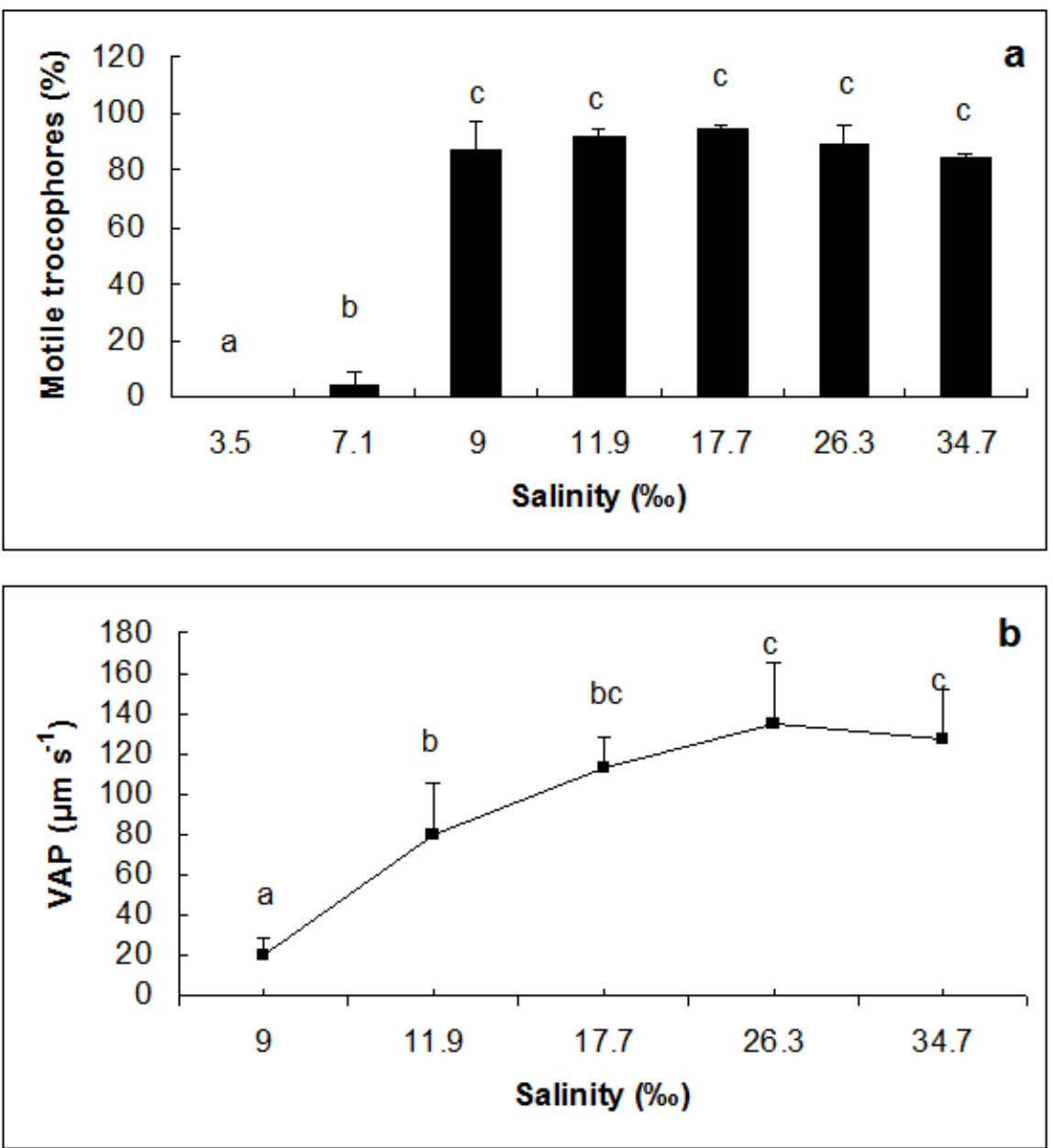
Fig. 4 Effect of $\mathrm{pH}$ on the movement characteristics of Pacific oyster trochophores ( $\mathrm{n}=3$ females, more than 30 trochophores observed for each film recorded); a: changes in the percentage of motile trochophores in relation to $\mathrm{pH}, \mathrm{b}$ : changes in the Velocity Average Path (VAP) in relation to $\mathrm{pH}$.
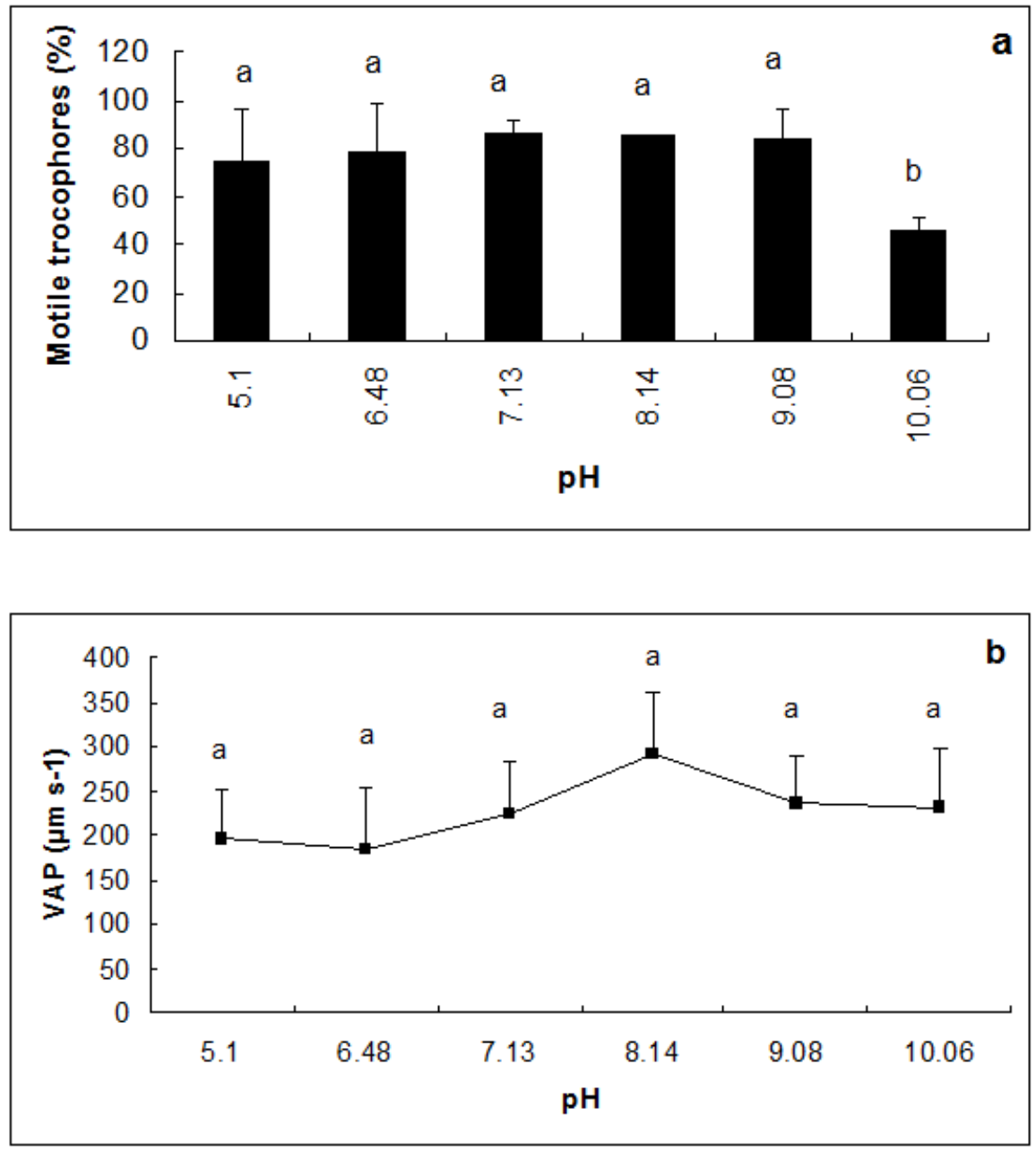